\title{
Preliminary Study of Coagulation Monitoring by Antenna for Treatment during Microwave Coagulation Therapy
}

\author{
Kazuyuki Saito ${ }^{* 1}$ and Koichi Ito ${ }^{2}$ \\ ${ }^{I}$ Research Center for Frontier Medical Engineering, Chiba University, Chiba, Japan \\ ${ }^{2}$ Graduate School of Engineering, Chiba University, Chiba, Japan
}

\begin{abstract}
Microwave coagulation therapy (MCT) has been employed mainly for treatment of small size tumors. In the treatment, thin microwave antenna is inserted into the tumor and microwave energy heats up the tumor up to at least $60^{\circ} \mathrm{C}$ for generation of enough coagulated volume including the target tumor. During the microwave radiation, reflection coefficient of treatment antenna changes significantly. In this paper, possibility of coagulation monitoring was found observing the reflection coefficient change of the antenna by numerical calculations and measurements.
\end{abstract}

Keywords: Microwave coagulation therapy, interstitial heating, thin antenna, reflection coefficient, finite-difference timedomain (FDTD) calculation.

\section{INTRODUCTION}

In recent years, various types of medical applications using microwaves have widely been investigated and reported [1]. In particular, minimally invasive microwave thermal therapies using thin coaxial antennas are of great interests. They are microwave coagulation therapy (MCT) [2] and interstitial microwave hyperthermia [3] for medical treatment of cancer, cardiac catheter ablation for ventricular arrhythmia treatment [4], thermal treatment of benign prostatic hypertrophy (BPH) [5], etc. Up to now, the authors have been studying such thin coaxial antennas especially for the MCT [6] and the interstitial microwave hyperthermia [7].

MCT has been employed mainly for the treatment of hepatocellular carcinoma [2]. In the treatment, a thin microwave antenna is inserted into the tumor, and the microwave energy provided by the antenna heats up the tumor to generate a coagulated region including the target cancer cells. The input power and the radiation time of the microwave energy are several tens of watts and a few minutes or longer, respectively, for generation of enough coagulated volume.

During the treatment, coagulated region including the target cancer cells are observed in real time by an ultrasonograph without temperature measurement. As progression of tissue coagulation, physical properties of the tissue clearly changes, so, the coagulated region can be observed by the ultrasonograph. However, in some cases, clear images cannot be obtained due to bubbles and gasses by water evaporation and carbonization of the tissue. Therefore, possibility of coagulation monitoring during the treatment by observation on reflection coefficient of treatment antenna will be considered. If it is possible, variation of the reflection coefficient helps exact estimation of tissue coagulation with an image by the ultrasonograph.

*Address correspondence to this author at the Research Center for Frontier Medical Engineering, Chiba University, Chiba, Japan; Tel: +81-43-2903328; Fax: +81-43-290-3933; E-mail: kazuyuki_saito@faculty.chiba-u.jp
For this consideration, the reflection coefficients of the antenna inserted into normal and coagulated swine liver tissue are calculated. Moreover, the same characteristics of the antenna are also measured during microwave radiation i.e. tissue coagulation.

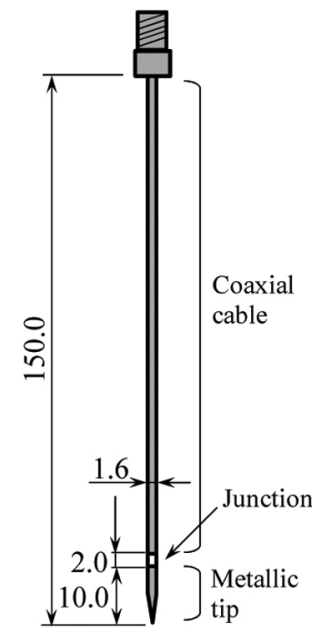

Conventional antenna

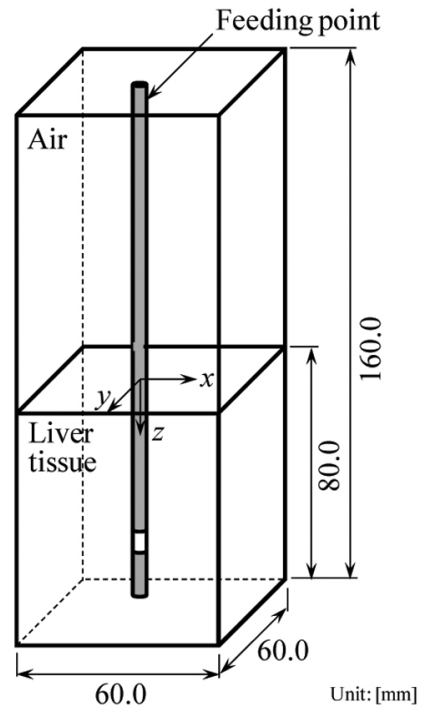

Analytical model
Fig. (1). Antenna and analytical model.

\section{ANALYTICAL MODEL}

\section{Numerical Calculation Model}

Fig. (1) shows the microwave antenna for the MCT and its analytical model for the calculation of reflection coefficient. In this study, a conventional antenna for treatment is selected. This antenna consists of a coaxial line and a metallic tip. In the analysis, the antenna is vertically inserted into the swine liver tissue. The operating frequency of the antenna is $2.45 \mathrm{GHz}$, which is one of the industrial, scientific, and medical (ISM) frequencies in Japan. In this 
paper, two types of liver tissue models are employed. The "normal model" is an uniform liver tissue and the "coagulated model" consists of three different media such as normal, coagulated, and carbonized parts. Fig. (2) illustrates the "coagulated model" around the antenna tip. Three parts are located on concentric cylinder and their sizes are defined by an experiment described in next section. The electrical properties of swine liver tissue are listed in Table 1, which are measured by Agilent $85070 \mathrm{E}$ dielectric probe kit. In the measurement, swine liver tissues in a nylon bag were put into hot water (approximately $70{ }^{\circ} \mathrm{C}$ ) bath to generate the coagulated region. In addition, the tissues were roasted to produce the carbonized part. From Table 1, it is observed that electrical properties (relative permittivity and conductivity) of the coagulated and the carbonized tissues are lower than the normal tissue because of reduction of water content in the tissue.

The finite-difference time-domain (FDTD) method [8] is employed for the calculations. In this technique, the Maxwell's equations are solved numerically in the time domain on a spatial grid. In the calculations, nonuniform cells are employed and small size cells are used only for the antenna and its vicinity. Here, the antenna part is constructed by fine cells without any simplifications. An outer boundary condition of the analytical model is Mur's first order. In addition, Gaussian pulse is excited between inner and outer conductors at the feeding point of the antenna for impedance calculations. The parameters for the FDTD calculations are listed in Table 2.

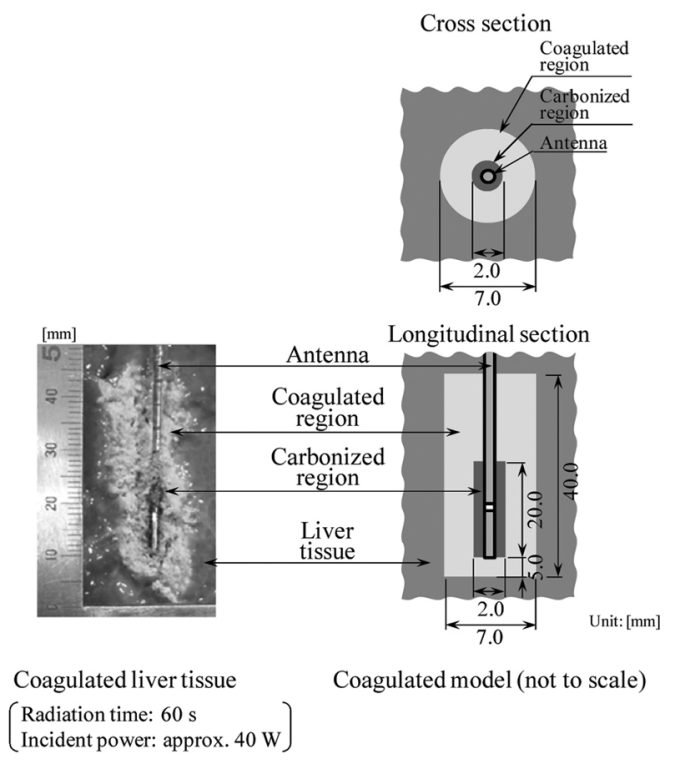

Fig. (2). Analytical model around antenna tip.

Table 1. Electrical Properties of Swine Liver Tissue

\begin{tabular}{|c|c|c|}
\hline & Relative permittivity $\boldsymbol{\varepsilon}_{\mathbf{r}}$ & Conductivity $\boldsymbol{\sigma}[\mathbf{S} / \mathbf{m}]$ \\
\hline \hline Normal part & 46.5 & 1.85 \\
\hline Coagulated part & 30.6 & 1.39 \\
\hline Carbonized part & 6.0 & 0.19 \\
\hline
\end{tabular}

Table 2. Parameters for FDTD Calculations

\begin{tabular}{|c|c|c|}
\hline Cell size [mm] (minimum) & $\begin{array}{c}\Delta x, \Delta y \\
\Delta z\end{array}$ & $\begin{array}{c}0.05 \\
\text { (const.) }\end{array}$ \\
\hline Cell size [mm] (maximum) & $\begin{array}{c}\Delta x, \Delta y \\
\Delta z\end{array}$ & $\begin{array}{c}1.5 \\
\text { (const.) }\end{array}$ \\
\hline Time step [ps] & $\Delta t$ & 0.117 \\
\hline Absorbing boundary condition & \multicolumn{2}{|c|}{ Mur (1st. order) } \\
\hline
\end{tabular}

\section{Experimental Setup}

Fig. (3) shows the experimental setup. The antenna is inserted into a swine liver tissue with $70 \mathrm{~mm}$ depth. The incident power of the antenna and the radiation time are approximately $40 \mathrm{~W}$ and $60 \mathrm{~s}$, respectively. Here, incident and reflection microwave powers are observed every $10 \mathrm{~s}$ by microwave power reflection meter (Rohde \& Schwarz NRT, NRT-Z44) during the microwave radiation for calculation on the reflection coefficient $\left(S_{11}[\mathrm{~dB}]\right)$ of the antenna.

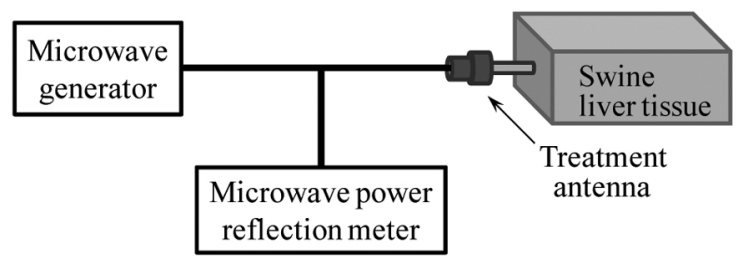

Fig. (3). Experimental setup.

\section{RESULTS}

Fig. (4a) shows calculated and measured reflection coefficients of the antenna during microwave radiation. The measured result of each time is averaged value of ten cases. In the calculations, two results of reflection coefficients were evaluated, which are before and after the radiations by the "normal model" and the "coagulated model", respectively. From these results, it is observed that the reflection coefficients rise with progression of tissue coagulation in both results of the calculations and the measurements. The error bars indicate the variation of measured reflection coefficient in each time. In addition, the calculated reflection coefficient of "before radiation" is approximately $-20 \mathrm{~dB}$ and the reflection coefficient of "after radiation" is almost the same as the measurement of $t=60 \mathrm{~s}$. Here, difference of reflection coefficient between before and after the radiation is approximately $5 \mathrm{~dB}$ in measurement. Moreover, Fig. (4b) shows the variation of reflection power of the antenna during the radiation. From the result, the difference of reflection power between before and after the radiation is approximately $5 \mathrm{~W}$, which is a sufficient difference for detection of coagulation.

As shown above, the clear difference of the reflection coefficients was observed between before and after radiations in both calculation and measurement. Therefore, it can be said that the calculation model of this study simulates the tissue coagulation well. 
a

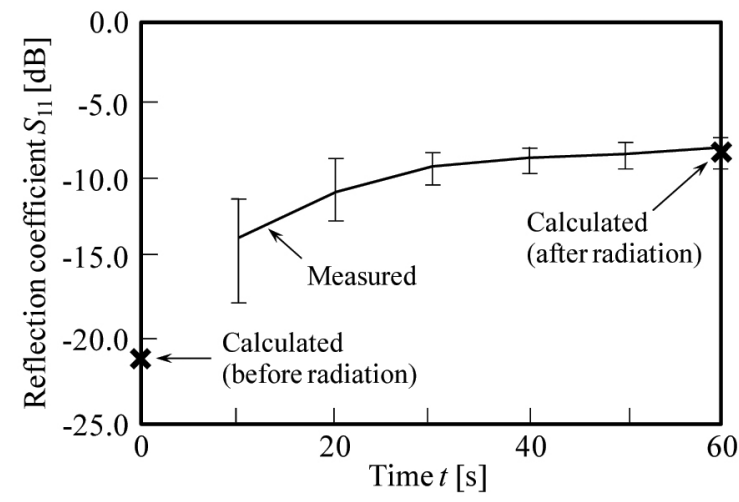

b

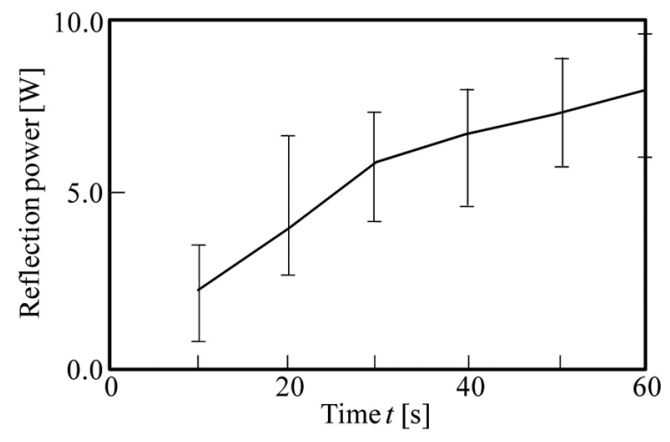

Fig. (4). a. Reflection coefficients $\left(S_{11}[\mathrm{~dB}]\right)$ of antenna during microwave radiation. b. Reflection power of antenna during microwave radiation (incident power of the antenna: approximately $40 \mathrm{~W}$ ).

\section{CONCLUSION}

Possibility of coagulation monitoring during MCT was found by observing the reflection coefficient of treatment antenna due to it clearly changed before and after the tissue coagulation. From these results, it is considered that this technique can supplement the current real time monitoring by the ultrasonograph. Therefore, relation between the values of reflection coefficients and the coagulated volume around the antenna should be investigated, as a further study.

\section{ACKNOWLEDGMENTS}

The authors would like to thank Mr. Takumi Hiraoka and Mr. Takahiro Kawamura, Graduate School of Engineering, Chiba University, Chiba, Japan, for their valuable assistance.

\section{REFERENCES}

[1] F. Sterzer, "Microwave medical devices", IEEE Microw. Mag., vol. 3, pp. 65-70, 2002

[2] T. Seki, M. Wakabayashi, T. Nakagawa, T. Itoh, T. Shiro, K. Kunieda, M. Sato, S. Uchiyama, K. Inoue, "Ultrasonically guided percutaneous microwave coagulation therapy for small carcinoma", Cancer, vol. 74, pp. 817-825, 1994.

[3] M.H. Seegenschmiedt, P. Fessenden, C.C. Vernon (Eds), "Thermoradiotherapy and thermo -chemotherapy", New York: Springer-Verlag, 1995

[4] R.D. Nevels, G.D. Arndt, G.W. Raffoul, J.R. Carl, A. Pacifico, "Microwave catheter design", IEEE Trans. Biomed. Eng., vol. 45, pp. 885-890, 1998.

[5] D. Despretz, J.C. Camart, C. Michel, J.J. Fabre, B. Prevost, J.P Sozanski, M. Chivé, "Microwave prostatic hyperthermia: interest of urethral and rectal applicators combination - Theoretical study and animal experimental results", IEEE Trans. Microw. Theory Tech., vol. 44, pp. 1762-1768, 1996.

[6] K. Saito, Y. Hayashi, H. Yoshimura, K. Ito, "Heating characteristics of array applicator composed of two coaxial-slot antennas for microwave coagulation therapy", IEEE Trans. Microw. Theory Tech., vol. 48, pp. 1800-1806, 2000.

[7] K. Saito, H. Yoshimura, K. Ito, Y. Aoyagi, H. Horita, "Clinical trials of interstitial microwave hyperthermia by use of coaxial-slot antenna with two slots", IEEE Trans. Microw. Theory Tech., vol. 52, pp. 1987-1991, 2004

[8] K.S. Yee, "Numerical solution of initial boundary value problems involving Maxwell's equations in isotropic media", IEEE Trans. Antennas Propag., vol. AP-14, pp. 302-307, 1966.

(C) Saito and Ito; Licensee Bentham Open.

This is an open access article licensed under the terms of the Creative Commons Attribution Non-Commercial License (http://creativecommons.org/licenses/by-nc/3.0/) which permits unrestricted, non-commercial use, distribution and reproduction in any medium, provided the work is properly cited. 